\title{
O JOGO EDUCATIVO NA EDUCAÇÃO INFANTIL.
}

\author{
Valéria Cristina Giacometti ${ }^{1}$, Rosiclaire Barcelos ${ }^{1}$, Carmen Lúcia Dias ${ }^{2}$ \\ ${ }^{1}$ Discente do Mestrado em Educação da Universidade do Oeste Paulista - UNOESTE. ${ }^{2}$ Docente do Mestrado em \\ Educação - UNOESTE. E-mail: lelagiacometti@hotmail.com ${ }^{1}$
}

\section{RESUMO}

O presente artigo tem como objetivo destacar a importância dos jogos na educação infantil. A partir da leitura especializada que aborda essa temática, investigou-se o desenvolvimento cognitivo da criança para um melhor entendimento do jogo infantil. Primeiramente analisou os comportamentos motores da criança e, como este contribuiu para o desenvolvimento da inteligência e na construção do conhecimento científico. Evidencia-se também, os benefícios da prática dos jogos infantis para profissionais e educadores que trabalham com a educação infantil. Deu-se prioridade para o jogo e o desenvolvimento intelectual da criança, e como esta se desenvolve nas suas habilidades, criatividade, sociabilidade e moralidade, Portanto, conclui-se que os jogos apresentam significativa contribuição para o desenvolvimento infantil e para o processo de ensino e de aprendizagem, se fazendo cada vez mais necessária a sua inclusão nos programas educativos como ferramenta pedagógica para profissionais e educadores que trabalham com a educação infantil.

Palavras-chave: Criança, jogo, ações motoras, inteligência, conhecimento.

\section{INTRODUÇÃO}

Não há como negar o benefício dos jogos para o desenvolvimento infantil bem como para o processo de ensino e de aprendizagem, envolvendo os aspectos cognitivo, afetivo, físico motor e moral. O presente trabalho investigou o desenvolvimento cognitivo da criança para um melhor entendimento do jogo infantil, nos seus comportamentos motores e como este contribui para o desenvolvimento da inteligência e na construção do conhecimento científico. Analisou-se também, os benefícios da prática dos jogos infantis para profissionais e educadores que trabalham com a educação infantil.

O trabalho apresenta duas seções: na primeira seção trata-se do desenvolvimento infantil; nele apresentamos os conceitos dos autores estudados sobre o desenvolvimento cognitivo da criança. Discutem-se principalmente os estágios de desenvolvimento da criança, desde o seu nascimento até a adolescência.

A segunda seção trata da importância do jogo infantil, numa visão mais piagetiana e outros teóricos especializados na educação infantil, dentre eles Friedmann e Wallon. Deu-se prioridade para o jogo e no funcionamento intelectual da criança, e como esta se desenvolve nas suas habilidades, criatividade, sociabilidade, moralidade. 


\section{O DESENVOLVIMENTO COGNITIVO INFANTIL}

O desenvolvimento da criança é analisado segundo os seus movimentos, em vários períodos de sua vida; um período começa onde o outro termina, em processo, um completa o outro. A princípio, estamos nos referindo aos comportamentos motores, ou seja, como as crianças desenvolvem a sua inteligência na construção do conhecimento científico.

Para uma melhor compreensão da prática diária dos profissionais que trabalham com a educação infantil ou com crianças é importante ressaltar que a infância é um período muito intenso de atividades, as fantasias e os movimentos corporais ocupam quase todo o tempo da criança. Piaget (s/d p. 16) explica o que é Esquema motor: "chamaremos de esquema de ações o que, numa ação, é assim transponível, generalizado ou diferenciável de uma situação a seguinte, ou seja, o que há de comum nas diversas repetições ou aplicações da mesma ação".

Ao nascer, a criança é caracterizada por uma atividade do tipo automática, movidas por ações reflexas, este primeiro estágio Piaget (s/d p. 16) chama de sensório-motor, é um estágio extremamente rico onde podemos perceber conquistas cotidianas ou pequenos passos muito complexos na vida da criança. Este estágio sensório motor, vai desde o nascimento até por volta de dois anos de idade; são ações de atividades do tipo automáticas, movidas por ações reflexas que a criança vai construindo, primeiro para receber as formas de se alimentar, para sobreviver, além de formar e desenvolver recursos vitais.

A estas formas ou melhor as primeiras ações de vida da criança Le Boulch (1981, p. 42) chama de corpo submisso "se parecem mais a crises motoras do que a movimentos orientados". Ainda nestes primeiros meses de vida da criança ela já começa a desenvolver as primeiras ações reflexas tais como: sugar; agarrar; começam a dar lugar a movimentos intencionais. Para Piaget (s/d p. 16) a criança começa a se libertar das primeiras ações ou expressões reflexas e começa a dar lugar ao aprendido; ou seja; por volta dos nove meses ela já começa a perceber que o objeto está ali, aqui os esquemas motores vão dando lugar às representações mentais.

Para Piaget (sd. p. 16) no primeiro ano de vida da criança, que vai do nascimento até os surgimento da linguagem, este período é chamado de sensório-motor. Nele podem ser distinguidos três estágios: "o dos reflexos, o da organização das percepções e o da inteligência propriamente dita".

Este período vai sendo superado pelo próximo e se dá até por volta dos dois anos de idade. Já o próximo período Piaget chama de pré-operatório que vai dos dois anos de idade até mais ou menos sete anos. É neste período que a criança tem a capacidade de pensar e ela entra no mundo 
da linguagem e das representações, como por exemplo: a criança com dois anos ela já se reconhece no espelho.

É um período extremamente rico, pois é a entrada no mundo da moralidade (o que é certo ou o que é errado). Não podemos esquecer que este período ainda a criança tem dificuldade do ponto de vista do outro é o que Piaget chama de egocentrismo, como por exemplo: você conta uma história para uma criança de mais ou menos cinco anos de idade, ela conta de volta a mesma história, como os outros já soubessem da história.

Já o terceiro período Piaget (s/d) denomina de estágio operatório, que se inicia por volta dos sete anos; é neste período que a criança tem suas ações interiorizada reversível, isto é, a criança pode pensar no que fez e voltar nas suas ações. Portanto, a partir dos sete anos este estágio se divide em dois: concreto e formal. No estágio concreto a criança faz uso de suas operações concretas; já no estágio formal a criança trabalha com hipóteses, externas de sua vivência.

Para Le Boulch (1982) é quando surge a função de interiorização, que permite a criança tem mais consciência dos aspectos do seu corpo e expressa-los verbalmente através da função simbólica. É através da linguagem que a criança coordena suas ações interiores (pensar, raciocinar), porém este raciocínio ainda enfrenta as mesmas dificuldades para se desenvolver, que enfrentaram os esquemas de ações, como por exemplo: engatinhar, andar etc.

Segundo Piaget (1977) é neste período (operatório-concreto) que se dá a preparação das operações lógico matemáticas; por volta dos seis aos sete anos de idade. A criança passa de um estado do centro de todas as coisas, para um estado de relacionamento com os outros, de tarefas coletivas, de maior socialização; ao que o autor chama de operatório-concreto, estágio marcado pelo raciocínio lógico, pelas regras e pela cooperação.

Colaborando, Freire (1994, p. 33) argumenta que:

É nesse período operatório-concreto, o poder de ultrapassar os limites da prática, o que começa a acontecer com o ingresso na puberdade ou na adolescência. Coincide com a experiência de uma criança de primeira a quarta série do ensino fundamental... em termos de idade, diríamos que ele vai dos seis aos sete anos de idade, até os dez a doze anos de idade aproximadamente.

Por fim, o estágio das operações formais e da inserção afetiva e intelectual num mundo adulto (Piaget, 1977). 
Para melhor entender sobre a importância dos jogos para o desenvolvimento e educação infantil, fez-se uma breve contextualização do desenvolvimento cognitivo da criança, para que se possa saber mais sobre como esta se desenvolve nas suas ações inteligentes.

\section{OS JOGOS NA TEORIA DE PIAGET}

Um dos estudos mais importantes sobre o jogo infantil está na obra de Piaget em a "Formação do símbolo na criança". Piaget (1971) faz uma análise e esclarece as relações entre o jogo e o funcionamento intelectual da criança, relatando seis formas utilizadas no jogo: 1) o jogo encontra sua finalidade em si mesmo. O jogador se preocupa mais com o resultado do que com o jogo em si mesmo. 2) é uma atividade espontânea, aqui o jogo não tem preocupação com nenhuma regra; 3) é uma atividade que dá prazer; 4) o jogo tem uma certa falta de organização; 5) aqui o comportamento da criança é livre de conflito, aqui o jogo ignora os conflitos; 6) o jogo tem uma motivação mais intensa.

Para esclarecer melhor sobre o jogo, recorremos à assimilação e acomodação. Estes dois movimentos, constituem funções constantes, atuando invariavelmente ao longo dos diferentes estágios de desenvolvimento mental por que passa o indivíduo, sempre em equilíbrio crescente.

Petruci (2001-2002), com a colaboração de Richmond coloca que a assimilação pode ser definida como processo de modificação dos elementos do meio, de forma à incorporá-los à estrutura do organismo. Constituiu o modo de ajustamento de novas experiências à mente. Por outro lado, a acomodação, é o processo de ajustamento do organismo às exigências do objeto que está tentando assimilar. Por meio desse processo, o sujeito reorganiza suas estruturas anteriores, de modo a enquadrar-se à nova experiência.

Esses processos formam parte de todas as ações da criança às vezes um predomina sobre o outro - como no caso do jogo simbólico; outros se encontram em equilíbrio.

Friedmann (1996, p. 27) explicita melhor sobre o jogo como:

“a expressão de uma das fases dessa diferenciação progressiva: é o produto da assimilação, dissociando-se da acomodação, antes de se reintegrar nas formas de equilíbrio permanente que dele farão complemento ao nível de pensamento operatório ou racional".

Piaget (1971, p. 207) analisa o jogo “(...) o jogo constituí o pólo extremo da assimilação do real ao eu". O jogo se dá nas diferentes fases do desenvolvimento da criança. Já o nascimento do jogo segundo Piaget (1971, p. 117) "quase todos os comportamentos (...) são suscetíveis de se converter em jogo uma vez que se repitam por assimilação pura, isto é, por simples prazer 
funcional como por exemplo: a criança joga a bola, pega e joga novamente, simplesmente por prazer".

Piaget (1978) aponta três sucessivos sistemas de jogo: de exercício, simbólico e o de regras. Os jogos de exercícios aparecem nos primeiros dezoitos meses de vida, e nas ações da criança envolve repetições de seqüências já estabelecidas das ações e manipulações pelo simples mero prazer funcional, derivados das ações motoras. Em torno de um ano de idade, os exercícios práticos tornam mais numerosos e vão diminuindo a importância, e começam a se transformar em outras formas: a) a criança passa a fazer combinações e repetições de suas ações e de manipulações, e os jogos de exercícios vão se transformando em construções; b) aqui os jogos de exercícios adquirem as regras explicitas e se transformam em jogos de regras.

Já os jogos simbólicos surgem no segundo ano de vida da criança, com o aparecimento da linguagem e vai até aproximadamente dos seis aos sete anos. A brincadeira do faz de conta é de início uma brincadeira solitária, dando lugar ao uso de símbolos como, por exemplo, o uso de brincadeiras de dramas, aqui o coletivo não aparece, ele só vai aparecer no terceiro ano de vida.

Piaget (1978) aponta três tipos de estrutura que caracteriza o jogo infantil e as classificam: o de exercício, o símbolo e a regra. Não podemos deixar de citar que os jogos segundo Friedmann (1996, p. 27) analisa os jogos de construção, num período de transição entre os três tipos de jogos e as condutas das crianças por elas adaptadas.

\section{Jogos de exercícios}

Para Piaget (1978) observa ao longo do período infantil três sucessivos sistema de jogo: de exercício, simbólico e de regras. O jogo de exercício, aparece durante os primeiros dezoitos meses de vida, aqui o jogo envolve a repetição de seqüências já estabelecidas de ações e manipulações da criança, pelo mero prazer de atividades motoras. Por volta de um ano de idade os exercícios práticos tornam-se mais numerosos e vão diminuindo sua importância para a criança. Os jogos começam a se transformar em outras formas: 1) a criança passa a fazer mais repetições e combinações de ações e de manipulações; depois os jogos de exercícios são transformados em construções; 2) os jogos de exercícios adquirem regras mais explicitas e, transformam-se em jogos de regras. 


\section{Jogos simbólicos}

Os jogos simbólicos surgem durante ao segundo ano de vida com o aparecimento da linguagem e da representação. De acordo com Piaget (1978) a brincadeira do faz de conta é uma atividade solitária e envolve o uso de símbolos: como por exemplo as brincadeiras sócio dramáticas aparecerão no terceiro ano de vida. Na visão piagetiana o faz-de-conta precoce envolve elementos com combinações e variam com o tempo; 1) comportamentos tais como dormir ou comer; 2) comportamento com outros colegas, dar de comer ou fazer dormir; 3) uso dos objetos substitutos, como blocos no lugar da boneca; 4) combinações seqüenciais, tais como imitações de ações que desenvolvem o faz-de-conta.

Com o aparecimento do jogo simbólico a criança ultrapassa a satisfação da manipulação, e vai começando a assimilar a realidade externa ao seu eu. Dessa forma, o jogo simbólico é usado como encontro de satisfação fantasiosa, por meio de compensação, de superação de conflitos e preenchimento de desejos.

\section{Jogos de regras}

O jogo de regra marca a transição da atividade individual para a socializada. Este jogo ocorre dos quatro aos sete anos e predomina no período de sete aos onze anos de idade.

Para Piaget, a regra pressupõe a interação de dois indivíduos e sua função é de se integrar ao grupo social. Piaget distingue dois tipos de regras: as que vem de fora e as que são construídas espontaneamente, o jogo espontâneo é representado pelos resultados da socialização, proveniente do jogo de exercício e do jogo simbólico.

Para Piaget (1971), a evolução das regras ocorre em três fases, sendo a primeira da anomia, encontrada em crianças de até cinco anos de idade, as quais não seguem regras coletivas. A segunda chamada heteronomia, em crianças de nove a dez anos de idade, onde as regras permanecem externas ao sujeito, prevalecendo o temor e o respeito ao sagrado. A terceira etapa, a criança tem mais autonomia, correspondendo uma concepção mais adulta do jogo, ou seja, as crianças jogam seguindo e respeitando as regras, no decorrer do jogo e assim criando novas regras. Sendo assim, as regras se apresentam dentro do sujeito, gerando o sentimento de respeito das mesmas.

É através dos jogos e brincadeiras que as crianças desenvolvem sua criatividade, habilidades, portanto, elas brincam em grupos ou individualmente; sendo brinquedos pedagógicos 
ou não, enriquecendo sua sociabilidade e sua capacidade de se tornarem seres humanos melhores e criativos.

\section{CONSIDERAÇÕES FINAIS}

Neste trabalho foi possível perceber a importância do desenvolvimento cognitivo da criança, a partir de suas ações práticas e como esta vai construindo em cada estágio suas conquistas inteligentes.

A significativa contribuição dos jogos para o desenvolvimento infantil e para o ensino e aprendizagem é evidente para este processo, se fazendo cada vez mais necessária a sua inclusão nos programas educativos como ferramenta pedagógica para profissionais e educadores que trabalham com a educação infantil.

É por isso que uma das qualidades mais importantes do jogo é a confiança que a criança tem quanto a capacidade de encontrar soluções. A ação de jogar é fonte de prazer e, ao mesmo tempo de conhecimento. É pela atividade lúdica que a criança se prepara para a vida e adquire a cultura do meio em que vive, coopera com seus semelhantes e convive como ser social.

\section{REFERÊNCIAS}

FRIEDMANN, A. Brincar e aprender. O resgate do jogo infantil. São Paulo: Moderna, 1996.

FREIRE, J. Educação de corpo inteiro. São Paulo: Sipione, 1994.

LE BOULCH, J. O desenvolvimento psicomotor do nascimento até 6 anos. Porto Alegre: Artes Médicas, 1982.

PETRUCl, M. das G. R. M. Psicogenética de Jean Piaget: algumas implicações didáticas. Pedagogia Cidadã/Unesp, 2001-2002, mimeo.

PIAGET, J. A formação do símbolo na criança: imitação, jogo, sonho, imagem e representação. Rio de Janeiro: Zahar, 1971.

A tomada da consciência. São Paulo: Melhoramentos/Edusp, 1977.

O nascimento da inteligência na criança. Rio de Janeiro: Zahar, 1978.

Seis estudos de psicologia. Rio de Janeiro: Forense/Universitária, s/d.

WALLON, H. Psicologia e educação da infância. Lisboa: Estampa, 1975. 